\title{
Case Study on the Deep Integration of Information Technology and English Curriculum
}

\author{
Yingxin Liu*, Yilin Wang
}

\author{
Shenyang University, Shenyang, Liaoning, 110044, China \\ *Corresponding author. Email: yingxin888@126.com
}

\begin{abstract}
It is of great theoretical and practical significance to explore the integration of information technology and curriculum from the perspective of specific subject teaching to improve the quality and efficiency of classroom teaching in China. At present, there are some problems in English teaching in China, such as timeconsuming and laborious teaching methods, low teaching effect and low comprehensive English level of students. Therefore, from the perspective of English teaching, the development of the research on the integration of information technology and subject curriculum not only has an important guiding role and practical significance for the reform of English teaching, but also is the actual need to promote the new curriculum reform and educational informatization.
\end{abstract}

Keywords: Information technology, English curriculum, deep integration

\section{INTRODUCTION}

He Kekang of Beijing Normal University believes that the so-called integration of information technology and curriculum is to create a new teaching environment by effectively integrating information technology into the teaching process of various disciplines, so as to realize a teaching and learning mode characterized by "autonomy, exploration and cooperation", which can not only play the leading role of teachers, but also fully reflect the dominant position of students [1].

In 2018, the Ministry of Education issued the 2 plan of action for education informatization, and put forward the detailed implementation plan and goal of "Internet plus education", aiming at basically achieving "three full, two high and one big" in 2022, that is, teaching application covers all teachers, learning application covers all the school-age students, digital campus construction covers all schools, and the level of information application and the improvement of information literacy of teachers and students are generally improved. The Internet plus education platform has been built [2]

The main purpose of this case study is to deeply understand the development of the integration of information technology and English Curriculum in the case school through questionnaire survey and interview, summarize the main problems in the integration process through the analysis of statistical data, interview records and classroom observation records, and then put forward suggestions for optimizing English teaching and deep integration of information technology and English curriculum combined with the actual situation of the case school Effective suggestions.

\subsection{Research Process}

The basic idea of this study is to collect detailed information through questionnaire survey, interview and classroom observation on the basis of the analysis of the integrated literature. On the basis of the analysis of the data, master the current situation of the integration of information technology and English Curriculum in the case school, explore the problems in the process of integration, and put forward feasible suggestions combined with the actual situation of the school as shown in Fig.1.

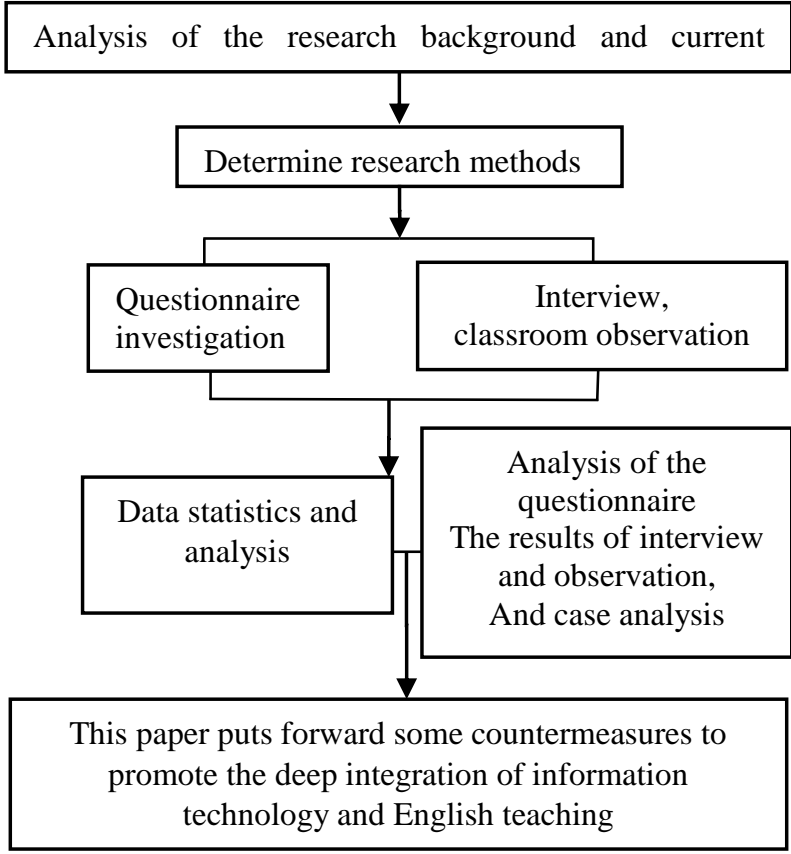

Figure 1 Research process. 


\section{RESEARCH CONCLUSION}

\subsection{Educational Information Technology Resource Platform is not Perfect}

In the information age, subject teaching resources mainly refer to the information resources that can run under the condition of multimedia computer or network, mainly including: network media materials, network question bank, test papers, courseware, network courses, teaching cases, FAQs and literature [3].

[interview record]:

1: Where do you usually search and use teaching resources?

T: I will use Baidu search before class, but the resources searched by Baidu are uneven. Some good teaching resources are not suitable for our school's version. Good versions have to be charged, and the resources of a class often come from different resource platforms.

Although there are many teaching resources at this stage, there is no perfect teaching resource platform that can integrate the existing excellent information technology teaching resources. Therefore, a resource platform with rich teaching resources integration becomes necessary.

\subsection{Teachers' Information Teaching Ability needs to be Improved}

English teachers' information-based teaching ability plays an important role in the integration of information technology and English curriculum. Through the questionnaire survey, it is found that $48.5 \%$ of the teachers have a general understanding of the theory of information technology and curriculum integration, and $9.6 \%$ have a comparative understanding. The total number of the two is more than half of the whole. Therefore, it can be seen that the teachers' understanding of information technology curriculum integration is not ideal. There are still a small number of students who hold a negative attitude towards the integration of information technology and English curriculum, and have a negative evaluation on the effect of integration, which shows that the positive effect of integration on students' learning is not applicable to all students, and information technology has not been effectively integrated into students' English learning. It also shows that teachers' information-based teaching ability, especially information-based teaching design the ability and the implementation ability of information teaching are still unable to meet the requirements of deep integration, and need to be further improved.

[teaching clip 1]

Step 1: warming up: revision and video

key points: Greetings.
T: Make a free talk and ask the students some questions about what they did. We can't ask students to pay attention to past the tense.

Questions: How was your weekend? Did you have a good time? What did you do last weekend? How was his/her weekend? What did he/she do?

Ss: Answer the questions and practice talking in past tense.

In this process, the main role of information technology is to show pictures and play videos. Teachers are the guides and technical operators, and students are the participants and appreciators.

From the case, we can see that the teaching materials are limited to teaching materials and teaching reference, lack of high-quality teaching resources from the network, and the richness of teaching content is slightly insufficient; secondly, lack of learning expanding knowledge, which can not meet the requirements of students with different ability levels. The use of information technology is relatively single, the learning content is mainly focused on the learning of textbook knowledge, and through a variety of activities to consolidate and deepen the learning of textbook knowledge, which meets the learning needs of most students, but can not meet the needs of students with higher ability level.

[interview record]:

1: What do you think of your IT capability? How long does it take to make courseware?

T: My information technology level is the general level of our grade group teachers. We have to start making courseware a few days before class. Some older teachers contact information technology later and spend more time.

Through the investigation and interview, it is found that although English teachers are proficient in teaching software and information technology tools, most of them spend a lot of time and energy on information retrieval and courseware making in teaching practice, which shows that most of them can not easily and effectively retrieve and process the existing information. The ability to retrieve and process information is the most basic component of teachers' ability to use modern information technology for teaching. If it is not effectively improved, it will not only affect the efficiency and effect of teachers' lesson preparation, but also affect the effect and process of integration.

\subsection{Students' Learning Ability Needs to be Improved}

In the questionnaire, $55.7 \%$ of the students have a general understanding of the teaching content of the Multimedia Technology Professor, and $3.7 \%$ are not familiar with it. The total number of the two is more than half of the whole. It can be seen that students' mastery of the courses taught by information technology is not ideal. 
The new basic education stage "English curriculum standard" puts forward: the focus of English curriculum reform is to cultivate students' interest in learning, advocate learning methods of experience, practice, participation, cooperation and communication, develop students' comprehensive language ability, form positive emotional attitude, active inquiry consciousness and autonomous learning ability, and lay a good foundation for students' lifelong learning and development Foundation [4].

Although students like to use the combination of information technology in English learning, they often use the app to learn English, but most of the current students play down the relevance and importance of information technology in English learning, which forms obstacles to the convergence of information technology and English learning. Students' self-control is not strong, and it is difficult to correctly choose and effectively distinguish various resources, and they are easily affected by all kinds of bad information and wrong information. "Learning should be an active and creative activity of students" [5]. Traditional English teaching takes textbooks as the only teaching resource, so students' learning is limited to textbook knowledge. In the face of limited and single learning resources, it is impossible for students to improve their English learning ability.

\section{RESEARCH COUNTERMEASURES AND SUGGESTIONS}

\subsection{Educational Information Technology Resource Platform is not Perfect}

\subsubsection{The construction of English subject teaching resource bank}

Subject teaching resource database is the crystallization of excellent subject teaching achievements in the process of education informatization, and the construction of subject teaching resource database is the key content of education informatization. The construction of subject teaching resource database directly affects whether resources can be fully and effectively used, and also profoundly affects the level of integration of information technology and subject teaching. At present, in order to meet the teaching needs of teachers, the school purchases the existing subject teaching resources. However, whether directly purchased or selfdeveloped, teaching resources need long-term dynamic accumulation, management and construction in order to truly become a good and bad subject teaching resource library.

\subsubsection{Combining the guiding ideology of Resource Co Construction and sharing}

Single or single school resources are difficult to give full play to the advantages of resources themselves, and can not build a good application platform. Therefore, the completed resources should be reintegrated to form a resource pool cluster, and form a complete resource system with educational public information resources, specialized multimedia resources, multimedia knowledge base and other basic resources.

The co-construction and sharing of excellent regional and school education resources is an important part of the construction of national education resource database, and also an important basis for the development of China's education resources. It is necessary to establish the guiding ideology based on the daily accumulation of resources and the co construction and sharing of resources, establish an orderly and effective organization and management mechanism, and mobilize English teachers to actively participate in the construction of subject teaching resources. Cultivate the awareness of cooperation and communication. Teachers are not simply "teaching materials", but "teaching materials".

\subsubsection{Improving the management of resource sharing platform}

The integration of good teaching resources also needs a special person in charge to maintain and continue to improve, collect a variety of network resources that teachers think teaching effect is good, from the vertical point of view, to collect the network resources used by teachers over the years, classified by unit, to ensure that the classic excellent resources are not lost, and can be updated in time, to ensure the timeliness of resources Sex. Horizontally, each teacher has his own different teaching ideas and ideas. This platform should also collect the network resources of different teachers, so as to facilitate teachers to learn from each other and communicate with each other, and reduce the burden of teachers to find resources. In addition, this platform can also be open to students. Students can choose their favorite network resources and use them repeatedly to maximize the role of network resources in English teaching. 


\subsection{Improving English Teachers' Information- based Teaching Ability and Realizing the Normalization of Deep Integration}

\subsubsection{Strengthening English teachers' theoretical study of information technology and English Teaching}

Educational technology training should take deepening basic education curriculum reform, reforming English teaching practice, accelerating the pace of in-depth integration of information technology and education, and improving teachers' professional ability as its ultimate goal and pursuit. According to the actual teaching needs and different tasks of the trained teachers, the training should be carried out at different levels, so that each teacher can be improved on the original basis. The training content includes deepening teachers' understanding of information technology theory and integration theory and improving teachers' information teaching ability. In the process of training, information collection and sorting, multimedia courseware making, web page making and teaching software learning and operation training are carried out, so that teachers can deeply understand the connotation of information-based teaching design in the training process, master the characteristics of excellent teaching design, and lay the foundation for improving the ability of information-based teaching.

\subsubsection{Strengthening English teachers' theoretical study of information technology and English Teaching}

In the process of training, we should not only pay attention to the operation and use of technical tools, but also pay more attention to the teaching function of technical tools, so that teachers can learn how to use information technology to support each stage of teaching, and effectively carry out information-based teaching practice and teaching evaluation. Teachers are encouraged to apply what they have learned, and constantly improve their level in the process of combining practice. In addition, let teachers learn based on specific teaching problems or actual teaching cases, and learn specific information-based instructional design cases through independent research and collective discussion, so as to stimulate teachers' interest in using information technology in teaching and enhance the effectiveness of training, which is conducive to teachers' learning for practical use. The way of training is mainly school-based training, and the combination of centralized training and scattered practice should be adhered to, so as to guide teachers' autonomous learning and practice, and give full play to the advantages of distance education, so as to ensure the quality and effect of training.

\subsubsection{Improving the quality of teaching by testing the results of teacher training}

Finally, it is necessary to test the effect of training in time in teaching practice, and test whether teachers have deepened the understanding and understanding of integration through lectures, seminars, open classes, basic skills of information teaching and other activities. English teachers can take the information technology and English curriculum integration assessment form developed by the school as a reference. On the one hand, they can use the indicators in the assessment form to check their teaching design and teaching plan, conduct self-evaluation, find the problems in their teaching design and constantly improve it. "Experience without reflection is narrow experience, which can only become superficial knowledge at most. [6] On the other hand, we should learn from excellent teaching design cases, carefully analyze and compare different excellent teaching designs, and then optimize our own teaching design and teaching plan in combination with our own teaching practice.

\subsection{Strengthening the Cultivation of Students' Information Technology Literacy}

\subsubsection{Creating a learning atmosphere conducive to students' active use of information technology}

Students' experience, feelings, creativity, brief introduction, problems and confusion are important material course resources, which have strong dynamic generation. We should timely capture and summarize them, so as to make them become the growth point of the teaching process.

When students use network resources for English learning, they must establish a correct view of resources, neither abuse network resources, nor refuse to use network resources, innovate ideas, actively try and use them appropriately. Therefore, we should strengthen the cultivation of students' information technology literacy, and educate students through some special courses and series of lectures, including the guidance of students' daily use of information technology in English learning.

\subsubsection{Reasonable selection and exploration of new teaching methods and models}

Starting from the teaching practice, according to the different characteristics of each student, we should teach students in accordance with their aptitude, and integrate information technology into English teaching as far as possible, so that students can understand the characteristics and functions of information technology in the learning 
process, and also make students better understand information technology and use it better.

When assigning autonomous learning tasks to students, we can appropriately assign some online learning tasks, such as searching materials and publishing articles, which should also be combined with due moral quality. Cooperative learning theory is constructed in learning style. The integration of information technology and English is very suitable for cooperative learning activities. In teaching, teachers mainly focus on "task driven", and pay attention to the cultivation of students' problemsolving ability, so that students can learn by "doing" and improve by "using".

\subsubsection{Make students deal with information from solving problems}

Learning by solving problems is the main way to use information technology in teaching. For example, we can set up cognitive conflict in the teaching process, let students use information technology to find problems and put forward solutions, arrange teaching reasonably, let students experience information processing, carry out communication and mutual cooperation. Establish interest groups, class exchanges and other ways to learn together and promote each other. Teachers should make full use of information technology to cultivate students' active learning literacy, properly use information technology to express their ideas, and actively carry out extensive exchanges and cooperation.

\section{CONCLUSION}

In short, the development of information technology promotes the development of English teaching. The Internet has broken the time and space of teaching, making English classroom face the world. Rich and vivid teaching resources stimulate students' interest and initiative in learning, help students better grasp the key points, break through the difficulties, and improve the learning effect. In the era of vigorously promoting information-based learning, teachers should recognize the advantages of information technology and make it clear that it is only an auxiliary means of classroom teaching. Teaching activities are still dominated by teachers with students as the main body. They should pay attention to the communication of students' real language and emotion, and appropriately apply information technology in classroom teaching, so as to effectively integrate information technology with English classroom teaching.

\section{ACKNOWLEDGMENT}

National publishing integration key laboratory, human education digital education research institute planning topic RJA0221001.

\section{REFERENCES}

[1] He Kekang. On the educational thought and philosophical basis of Constructivism -- Reflection on Constructivism [J]. Chinese university teaching, 2004 (7): 1. (In Chinese)

[2] Ministry of education of the People's Republic of China, education informatization 2.0 action plan, 2018. (In Chinese)

[3] Ministry of Education Modern Distance Education Resources Construction Committee. Modern distance education resources construction technical specification [S]. 2000 [5]. (In Chinese)

[4] New English curriculum standards of the Ministry of education of the People's Republic of China (experimental draft) Beijing: People's education press, 2004. (In Chinese)

[5] Colin Campbell, Hanna Kryszewska. Learner-based Teaching [M].Shanghai: East China Normal University Press, 1998. (In Chinese)

[6] Liu Jie. New curriculum and teachers' professional development in senior high school. Tianjin: Tianjin Education Press, 2005:88. (In Chinese) 